\title{
The Role of Organizational Identities for Policy Integration Processes: Managing Sustainable Transport Development
}

\author{
Linnea Eriksson
}

Journal Article

\section{Tweet}

N.B.: When citing this work, cite the original article.

This is a copy of the original publication which is available at www.springerlink.com:

Linnea Eriksson , The Role of Organizational Identities for Policy Integration Processes: Managing Sustainable Transport Development, Public Organzation Review, 2016.

http://dx.doi.org/10.1007/s11115-016-0348-0

Copyright: Springer Verlag (Germany)

http://www.springerlink.com/?MUD=MP

Postprint available at: Linköping University Electronic Press

http://urn.kb.se/resolve?urn=urn:nbn:se:liu:diva-134659

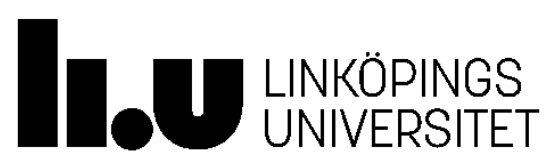


The Role of Organizational Identities for Policy Integration Processes - Managing Sustainable Transport Development

Linnea Eriksson, Linköping University, Department of Thematic Studies, Technology and Social Change

Accepted for publication in Public Organization Review in May 2016

\begin{abstract}
Sustainable transport development is a complex, but necessary issue to manage if the use of fossil energy will decrease and transportation become more energy-efficient and environmental friendly. The contemporary public organization is organized into policy sectors and tiers of government, but the issue of sustainability is not confined to one single sector or level, it transcends all these traditional boundaries. To address this complexity policy integration has been suggested as a way for public organizations to open up the sectoral and vertical boundaries in policymaking. This paper discusses a case study of a political committee on the regional level in Sweden, which has been formed for integrated policymaking between sectors and local and regional authorities to manage sustainable transport development. The members are thus representing different interests, here conceptualized as organizational identities. The aim of this paper is to understand the role and relations of organizational identities for sectoral and vertical policy integration processes. The study is based on qualitative analysis of official notes from meetings and 16 semistructured, in-depth interviews with stakeholders. The analysis of the case shows that vertical and sectoral integration are dependent processes and that the relation between different organizational identities either strengthens or undermine them. Vertical integration is not resulting in sectoral integration, rather it works prohibiting against sectoral integration.
\end{abstract}

Keywords

Organizational identity - Policy integration - Sustainable transport policy - Regional governance - Sweden

\title{
Introduction
}

The fossil energy usage in the world today is one of the major problems in relation to climate change. The transport sector accounts for $20 \%$ of global energy usage and fossil energy carriers dominates in the transport system (IEA 2014a; IEA 2014b; SEA 2015). Sustainable transport development is therefore a necessary issue that contemporary public organizations need to manage (Banister 2008; Hull 2011). It is an issue that transcend the traditional borders of policy sectors, organizations, and administrative levels, sometimes referred to as a cross-cutting issue (Stead and Meijers 2009). A suggested way to manage sustainability is policy integration (WCED 1987). It means that the traditional policy sectors and tiers of government, and the organizational structures they are consisting of, are opening up for more integration of actors and issues in policymaking processes (Hull 2008; Stead et al. 2004; Underdal 1980).

Sustainable transport development is a concern for several policy sectors in different ways. For economic development more transport possibilities and more people travelling is a condition for increasing economic development. For the environment, on the other hand, fossil fuel energy usage is a major problem which means that there is a need for more efficient transportation and for usage of alternative fuels and vehicles. To make transport more efficient it has been suggested that transport solutions are integrated into the land-use planning on local and regional levels (Stead and Meijers 2009). Policy integration concerning sustainable transport has been studied with focus on spatial planning, environment (Hull 2008; Stead et al. 2004), health (Stead 2008) and energy (Olsson et. al 2015) in urban areas. However, it is not only integration between sectors that might be of importance for sustainable transport development, but also the integration of different tiers of government. In this paper an interorganizational body on the regional level in Sweden is used as case to study both sectoral integration and the integration between regional and local levels.

To achieve sustainable transport development the regional policymaking should manage several policy sectors and policymaking levels. In Sweden the regional authority is one, but there are also several local municipalities with different interests in transport development due to their size, characteristics and their situation in relation to 
transport infrastructure. The region is also acting within and must relate to the national government's framework of goals and policies concerning transport development.

Earlier studies of policy integration in regions have had their point of departure in general goals of integrated policymaking and analyzing if these are met within the regular organizational structure of policy processes (see for example Hjalmarsson 2015; Hull 2008; Stead et al 2004). The case studied in this paper is a new organizational body formed to perform integration between both sectors and local and regional authorities to develop sustainable transport policy. It is thus a case of policy integration where both sectorial and vertical integration may be studied.

The case study is a regional committee in Sweden, formed to manage sustainable development issues of relevance to the region of Västra Götaland. The committee consists of regional authority representatives, presenting different policy sectors, and representatives for the municipalities situated within the region. The members represent several organizations and departments with different organizational identities. These different organizational identities are a precondition for policy integration processes to occur, but they may also play a role for its performance. The aim of this paper is therefore to understand the role and relations of organizational identities for policy integration processes of regional sustainable transport policy.

The paper starts with an introduction to the case of study. In the next part the theoretical framework is outlined: first the approach of policy integration is explained and then the analytical concepts of organizational identities and consensus and conflict are discussed. The third part describes the methods used to collect the material that is the basis for the study and how this material has been analyzed. In the fourth part the results of the study are described and analyzed, focusing on the different identities that are present in the committee. In the fifth and final part of the paper the findings are discussed, and conclusions from the case are drawn.

\section{Case study: The Sustainable Development Drafting Committee}

The case study is a political committee in the Swedish region Västra Götaland, the second largest region in Sweden in terms of population (RVG 2015a). The committee consists of politicians representing either the regional authority; Region Västra Götaland (RVG) or representatives of the four subregional assemblies consisting of the region's 49 municipalities. The committee is called The Sustainable Development Drafting Committee (SDDC) and is a body created for collaboration between the RVG and the municipalities (see Figure 1). Thirteen of the commissioners represent the RVG, and 16 commissioners represent the subregions. The subregional representatives are elected by the municipalities through their subregions, and each subregion has four representatives (SDDC Notes 15/02/2011). The RVG representatives in the SDDC are members of four different political committees within the RVG: the Executive Committee, Regional Development Committee, Environment Committee, and Culture Committee. The three last committees are sectoral committees responsible for specific issues or assignments. Each committee is supported by an administration of professionals within their sector. A more detailed description may be found in Table 1. 


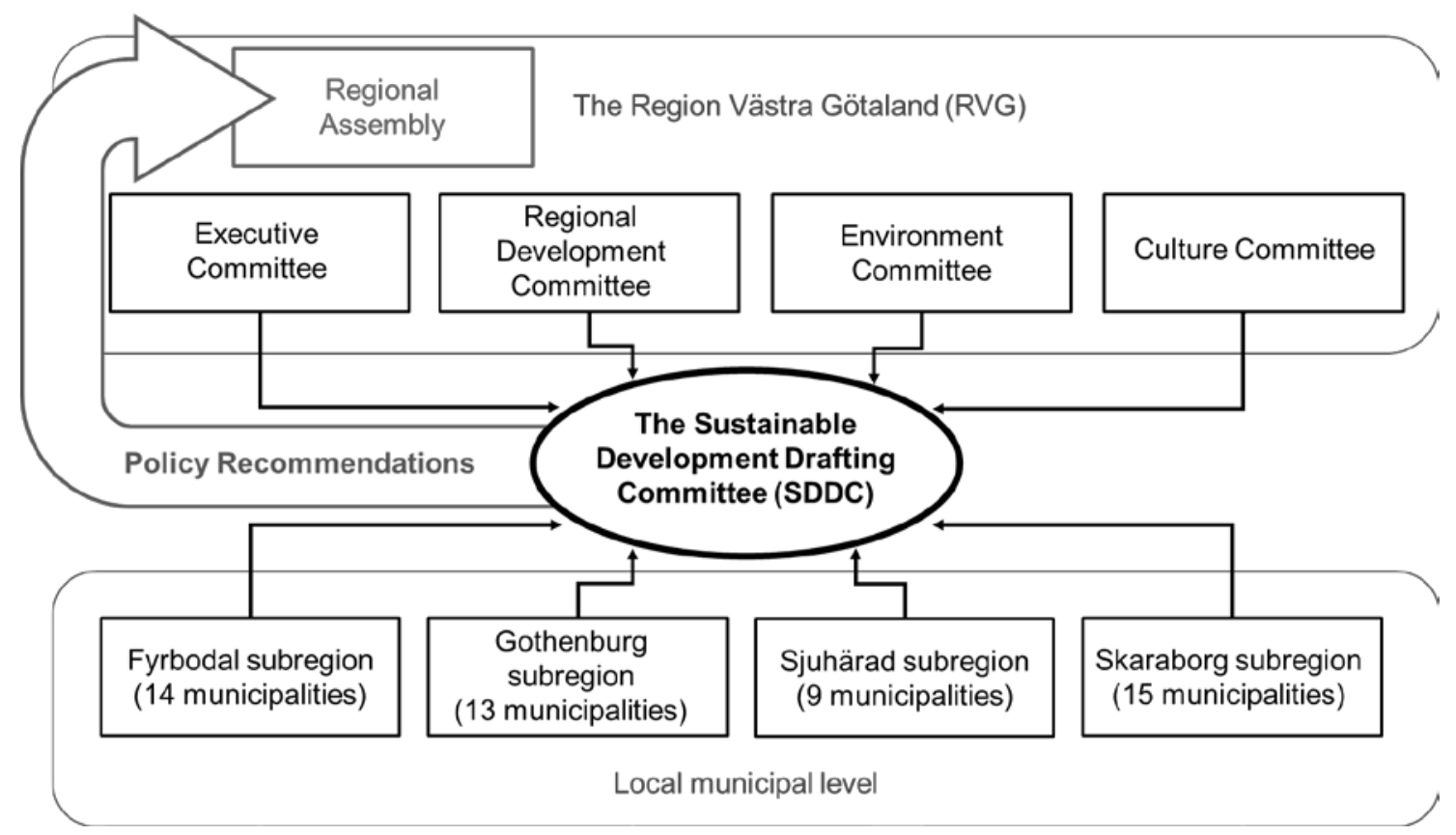

Fig. 1 Organizational structure of the SDDC

The SDDC is assigned to work as a platform for informal collaboration between the RVG and the municipalities. The committee's mandate is to develop recommendations for regional policymaking in the RVG, concerning issues of strategic and long-term impact germane to sustainable regional development. Sustainable transport development is one of these strategic issues (SDDC Instructions 2010: 1). Public transport is, however, not a task of the SDDC, as it is separately managed by another committee within the RVG. Apart from its given task, the SDDC is free to raise questions and produce recommendations concerning issues where the members consider the committee's views important for the RVG's management of the issue (SDDC Instructions 2010). The policy recommendations formed in the SDDC are then used in the RVG's Executive Committee and the Assembly as the basis for their decision-making (SDDC Instructions 2010).

Table 1 Description of the RVG committees represented in the Sustainable Development Drafting Committee (SDDC)

\begin{tabular}{|l|l|l|l|l|}
\hline & $\begin{array}{l}\text { Executive } \\
\text { Committee }\end{array}$ & Culture Committee & $\begin{array}{l}\text { Environment } \\
\text { Committee }\end{array}$ & $\begin{array}{l}\text { Regional } \\
\text { Development } \\
\text { Committee }\end{array}$ \\
\hline $\begin{array}{l}\text { Responsibility } \\
\text { within the RVG }\end{array}$ & $\begin{array}{l}\text { Committee with } \\
\text { overall } \\
\text { responsibility } \\
\text { within the RVG } \\
\text { and the body which } \\
\text { prepares decision- } \\
\text { making in the } \\
\text { Regional Assembly }\end{array}$ & $\begin{array}{l}\text { Committee with } \\
\text { responsibility for } \\
\text { issues related to } \\
\text { culture and its } \\
\text { development } \\
\text { within the RVG }\end{array}$ & $\begin{array}{l}\text { Committee with } \\
\text { responsibility for } \\
\text { the guiding } \\
\text { development } \\
\text { within the region } \\
\text { towards a more } \\
\text { environmentally } \\
\text { sustainable society }\end{array}$ & $\begin{array}{l}\text { Committee with } \\
\text { the responsibility } \\
\text { to fund efforts to } \\
\text { promote economic } \\
\text { development in the } \\
\text { region- } \\
\text { responsible for } \\
\text { regional transport } \\
\text { infrastructure } \\
\text { planning }\end{array}$ \\
\hline Members & $\begin{array}{l}\text { Full-time } \\
\text { politicians }\end{array}$ & $\begin{array}{l}\text { Full-time and part- } \\
\text { time politicians }\end{array}$ & $\begin{array}{l}\text { Full-time and part- } \\
\text { time politicians }\end{array}$ & $\begin{array}{l}\text { Full-time and part- } \\
\text { time politicians }\end{array}$ \\
\hline
\end{tabular}




\begin{tabular}{|l|l|l|l|l|}
\hline $\begin{array}{l}\text { Number of } \\
\text { representatives in } \\
\text { the SDDC }\end{array}$ & 3 & 3 & 3 & 3 \\
\hline
\end{tabular}

${ }^{1}$ Source for the facts in this row: RVG, www.vgregion.se.

Regions, municipalities and sub-regions

The regional level in Sweden has traditionally been weak, while the local level has a strong position in the Swedish constitution. The relationship between the regional and local levels is not hierarchical. They are rather responsible for different issues and policy sectors. However, the regional and local levels are at the same time more or less connected and thus mutually dependent. In Västra Götaland the regional authority, the RVG, has a directly elected regional parliament with jurisdiction over healthcare, public transport, regional transport infrastructure planning, and general regional (sustainable) development (RVG 2015c). The Swedish municipalities have jurisdiction over their local territory and is empowered by the right to tax everyone living within it (Rose and Ståhlberg 2005). Concerning regional sustainable transport development, the municipalities have one jurisdiction of great importance: the land-use planning monopoly. This means that they decide on location of property and industry and on transport infrastructure development within their territories (Nyström 2003). The RVG is thus dependent on the municipalities for implementation of regional transport policy. The municipalities, on the other hand, often lack resources such as investment capital and knowledge to be able to implement the transport developments they need.

In Västra Götaland the 49 municipalities are organized into four subregional assemblies for managing collaboration with the RVG, they are: Fyrbodal, Gothenburg, Sjuhärad, and Skaraborg (RVG 2011). Neighboring municipalities form a subregion and represent a certain geographic area within Västra Götaland. These subregional areas have both different and similar characteristics. The Gothenburg subregion is an urban area, the second largest in Sweden, and the self-evident center of Västra Götaland. Gothenburg has Scandinavia's largest seaport and the largest labor market in Västra Götaland. The other three subregions are mostly characterized by medium-sized and smaller cities as well as less densely populated areas such as farmland, forest, and coastland (RVG 2008). A more detailed description of the subregions may be found in Table 2. Each subregion serves as a collaboration platform for its member municipalities on issues where the municipalities need to cooperate with other actors to solve common problems. The subregions have an administration to support the collaboration and the external representation of the subregions.

Table 2 Description of the subregions

\begin{tabular}{|l|l|l|l|l|}
\hline & Fyrbodal & Gothenburg & Sjuhärad & Skaraborg \\
\hline Characteristics & $\begin{array}{l}\text { Small cities (< pop. } \\
70,000) \text { and } \\
\text { coastland and } \\
\text { woodland }\end{array}$ & $\begin{array}{l}\text { One large urban } \\
\text { area }\end{array}$ & $\begin{array}{l}\text { One city (pop. } \\
100,000) \text { and small } \\
\text { cities and farmland } \\
\text { and woodland }\end{array}$ & $\begin{array}{l}\text { Small cities and } \\
\text { farmland and } \\
\text { woodland }\end{array}$ \\
\hline Population ${ }^{1}$ & 260,000 & 927,000 & 310,000 & 260,000 \\
\hline $\begin{array}{l}\text { Members } \\
\text { Number of } \\
\text { representatives in } \\
\text { the SDDC }\end{array}$ & 4 & 13 municipalities & 9 municipalities & 15 municipalities \\
\hline
\end{tabular}

${ }^{1}$ Source for the numbers in this row: Johansson and Niklasson (2013).

Theoretical perspectives

The case will be analyzed using the theoretical concept of organizational identity in order to understand what the differences between the representatives in the committee may be based on. To be able to analyze the 
relationships between the present identities and also their relationship to the issue of sustainable transport development the concepts of conflict and consensus will be used. These perspectives and concepts are further described and discussed later in this part, before that, since the case is a case of possible integrated policymaking, the framework of policy integration is described.

Policy integration

Policy integration concerns the management of cross-cutting issues. Cross-cutting issues are challenging for all tiers of government, since they cannot easily be confined to one single policy sector or level of government and therefore imply necessary collaboration across the sectoral and vertical borders (Stead and Meijers 2009). Policy integration refers to cooperation, coordination and integration during policymaking processes between different departments, organizations, and professions to create either joint or complementary policy (Stead et al. 2004). It is about working together across borders to solve a common problem and develop policy that is not working contradictory. Because the risk with a cross-cutting issue, according to the policy integration literature (Ugland and Veggeland 2006), is that it is managed by separate policy sectors in parallel and due to their differences they end up with contradictory policies concerning the same issue.

Policy integration is possible along several dimensions (see Geerlings and Stead 2003 for an extended discussion), in this paper the focus is foremost on two of these dimensions: sectoral integration and vertical integration. Vertical integration refers to processes of integration in policymaking between different tiers of government: the local, regional, national or international levels (Geerlings and Stead 2003). The vertical integrated policymaking could be current within one sector or between several sectors. In this paper the focus is on vertical integration between the regional and local levels, hence the members of the committee are representing local and regional authorities. Sectoral integration refers to integration processes between two or more separated policy sectors in policymaking (Geerlings and Stead 2003). Policy sectors have been studied from many perspectives, in this paper the focus is on organizational identity.

\section{Organizational identities}

In studies of public organizations the relevance of identity for action within and between organizations has been recognized (Gioia et al. 2013; Selznick 1984). The general idea is that every organization has a certain identity which provide the individual with rules of appropriate behavior (March and Olsen 2008) in situations when the individual act for or within the organization. Organizational identity is therefore central to the ability of the organization to act as one unit and to the maintenance of the organization (Selznick 1984). Organizational identity should here be understood as “a guide for what an organization's members should do and how other organizations should relate to it” (Gioia et al. 2013, p. 161).

An organization's identity depends on both the internal and the external environment of the organization (Selznick 1992; Selznick 1996). The internal aspects of organizational identity are the founding beliefs and values, organizational narratives, and past experiences of members (Gioia et al. 2013). These internal aspects are valuable to the understanding of differences between organizations on different levels within the state. All municipalities are founded on the base of the same legal framework, but their specific characteristics form different narratives specific to every municipality. Therefore, municipalities may have one common organizational identity as an administrative body at the same time as they also have another organizational identity connected to its specific characteristics; such as if it is an urban or rural area, if there is access to highways and/or railways and if it rely on incoming commuting or is a place from where people commute. Regional authorities are based on another legal framework than the municipalities, making their founding principles and thus organizational identity different from the municipalities.

In the external environment there are two aspects of importance to organizational identity: the institutional context of the organization and the surrounding organizations (Gioia et al. 2013). The institutional context puts attention on external structures and social meanings that embed the organization in question (Glynn 2008). It should here be understood as the Swedish transport policymaking structure. The institutional context also connects the organization with other organizations (Scott 2014). Surrounding organizations are used to achieve legitimacy by emulating their identities (Gioia et al. 2013), or identifying itself in opposition to other organizations by making them "rivals" (Kroezen and Heugens 2012). In short, organizations define themselves 
as being like some organizations and unlike others (Gioia et al. 2013). Therefore, different municipalities that share internal characteristics may be able to form groups based on their common characteristics to be able to solve common problems.

One organization need not to have only one organizational identity, but large and complex organizations may host several different organizational identities (Humphreys and Brown 2002; Gioia et al. 2013). In the public organization these different organizational identities may be connected to different policy sectors (Hendriks 1999). The sectoral differences are based on a legal framework which is common to all departments acting within one sector, traditions and narratives within one sector that forms values specific to the sector, and the same professions managing one sector or part of it (cf. DiMaggio and Powell 1983). The differences in organizational identities may provide each sector with their own logics and traditions that shape their policy processes. This may make the sectors rather autonomous, even if they are the same as departments within the same organization (Hendriks 1999). That policy sectors have different organizational identities is one way of focusing on their differences for the analysis of policy integration processes.

Consensus and conflict

The approach of organizational identities is, however, not focusing on the relationships between the present identities and how these relationships influence the policymaking process. Therefore, the concepts of consensus and conflict originating from the policy network approach (Sørensen and Torfing 2007) are used to analyze policymaking in combination with the meaning of organizational identities. A policy network is a network of different actors that interact concerning certain policy issues which all the involved actors have an interest in and they develop policy through negotiations (Sorensen and Torfing 2007). In this paper the committee in focus has similar features with a policy network as it consists of members representing several different organizations.

In policy network approaches the internal dynamics of the members in the network are often conceptualized as consensus and conflict. Consensus is described as a necessary factor for the function and existence of a network: the participant actors agree on a certain framework for interaction within the network. Consensus contributes to getting the necessary work done, ensures that transaction costs are low, and makes complex issues manageable (Koppenjan 2007). Koppenjan (2007) discusses situations of an overload of consensus, which works against the network's functionality. The major consequence of a consensus overload within a network is that it becomes closed to the outside world, which has a number of negative implications (Koppenjan 2007). For example, there is a risk of new problems and new and innovative solutions being excluded and the interests of the members being met at the cost of public interest. Policies may therefore be designed and decided upon from a narrow sectoral view, and the possibilities for more integrated approaches are then limited. There is also a risk of nontransparency in policymaking and a lack of democratic accountability.

From this follows that a certain level of conflict is favorable for the functionality of networks. The presence of conflict may indicate that the network is open and not static, since there are possibilities to question the framework of the network and bring in other interests to the negotiations. Conflict may contribute to innovative solutions, as new problems are brought in and promote the transparency of the network's processes (Koppenjan 2007). This means that a balance between consensus and conflict is necessary for good functioning of public interorganizational settings. The members of such a body must, according to this recommendation, express their different interests and let their organizational identities guide their actions in order not to get a surplus of consensus, but to manage necessary conflicts within the network. Consequently, the literature on policy networks views the member organizations and their differences in identities as resources for the network.

The use of the theoretical framework on the empirical case

Policy integration forms the framework for this case study since the case is a possible case of policy integration. The committee in focus consists of representatives of several different organizations, representing sectoral and regional or local interests. Hence these different interests are the major reason for the committee's existence. The concept of organizational identity is used to understand their role in the policymaking process of sustainable transport development. The policymaking process is characterized by consensus and conflict and they also work as preconditions for what policy that can be achieved. The concepts of consensus and conflict are thus 
contributing to the organizational identity perspective to explain the identities' role in policymaking for sustainable transport development and also their role in policy integration processes.

\section{Materials and methods}

The case studied is that of a political committee with representatives from regional and local authorities and different sectors, with integrated policymaking concerning sustainable development as its task. It should be understood as a critical case (Flyvbjerg 2001) of integrated policymaking. It presents an organizational body where it is most likely that policy integration is performed. More specifically, the case is valuable for understanding how sustainable transport development is managed in an organization for integrated policymaking.

Because of the character of the case, an explorative approach was applied (Kvale and Brinkmann 2009). The case study was conducted from November 2012 through February 2013 and consists of the analysis of interviews and documents. When collection of all the empirical material was completed, a first analysis of it revealed the relevance of different identities. Then, useful theoretical perspectives on identities and policy networks were used for a second theoretical analysis of the material.

A total of 16 in-depth interviews with politicians and officials at the Region Västra Götaland (RVG) and at four subregions were conducted. Nine of the respondents are participants in the political committee in focus. Three officials connected to the political committee were interviewed. They work with the issues managed by the committee at either the regional or the subregional level. Three respondents, two politicians and one official, are not members of the committee in focus and do not work directly with it. They were chosen to be interviewed because of their involvement in public transport, which is the only transport issue not managed by the committee in focus. As representatives for the public transport sector at the RVG, they were able to provide an outsider's perspective of the committee and reflect on its impact on regional transport policy in general.

The interviews were about sustainable transport development in a general sense and not only about the work within the specific committee. The respondents gave a nuanced picture of the work practice within the committee and stressed what advantages and problems there are from many perspectives. The interviews conducted were semistructured, with a low level of standardization. An interview guide was used, where the questions were ordered thematically (Kvale and Brinkmann 2009). The questions were open in character to encourage the respondents to describe certain situations or concepts in detail. The interviews were conducted by one interviewer and lasted about 40-90 minutes each. The interviews were analyzed using meaning condensation, that is, each transcript was read through, and then passages from it were condensed into shorter statements. These statements could then be thematically sorted into thematic descriptions of identities (Kvale and Brinkmann 2009). The interviews are referred to in the following text by using an "I" and a number to indicate the exact interview (Appendix 1).

To complement the interview statements, documents, with official notes from the committee meetings, were also studied. These were analyzed qualitatively to extract the content and meanings of the discussions (Tesch 1990). Other documents describing transport policy and general policy development, as well as protocols from meetings, in the RVG, the subregions, and other relevant organizations have also been used for background information and confirmation of interview statements. All empirical sources referred to in the following text can be found in Appendix 1.

Sustainable Development Drafting Committee - the role of the committee and of organizational identities for sustainable transport development

In this part the findings of the analysis of the case of the Sustainable Development Drafting Committee (SDDC) will be described, discussed and analyzed. First, the role of the committee within the region and in the Swedish institutional context is explained. Second, three organizational identities current in the committee are discussed. The conclusions drawn from this analysis of the SDDC and the implications for policy integration are then discussed and summarized in the following concluding discussion. 
The formation of the SDDC—an external and internal resource

To manage the issue of sustainable regional development in general and more specifically sustainable transport development, the SDDC is in an ongoing process of organizational formation. How the members of the SDDC act and how they decide to act together plays an important role for the significance of the SDDC, both in the internal regional policymaking and in national policymaking.

The SDDC's members represent the region of Västra Götaland, or, for the municipal representatives, their subregion, and not the RVG as an organization, their municipality or their party. The Committee is not a formal decision-making body, but formal decisions [...] are taken by the Regional Executive Committee or the sectoral Committee concerned. [...] Notwithstanding this, it should be stressed that the position taken by a unanimous Committee weighs very heavily in the RVG's continuing handling of each issue. (SDDC Notes 15/02/11)

As shown in the quotation above the formal rules for representation in the SDDC are clear: a common "regional" interest and four subregional interests should be used as a basis for decision-making (SDDC Notes 15/02/2011). The background to these formal rules is the founding idea of the SDDC, that it should be understood as a neutral, regional arena relevant for all of Västra Götaland. It should be an organization for development of decisions that are in line with what is best for the entire region (SDDC Instructions 2010).

In the quotation above the last sentence emphasizes the essential position of the SDDC in regional policymaking: a unified committee has major impact on regional policy, since the RVG's decisions almost always follow the SDDC recommendations, at least when the SDDC has reached consensus among its members (SDDC Notes 15/02/2011, I3, I7, I13). Reaching consensus is thus central to the SDDC's relevance in regional policymaking and therefore important to the members. The importance of consensus-making becomes evident in the descriptions by SDDC members of when subregional identities are expressed and enforced, regardless of how they correspond to the development in the whole region: neither subregional nor RVG representatives like those situations, since it results in conflicts between subregions and between subregions and the RVG.

Consensus-making is needed not only for the SDDC's internal position in regional policymaking but also for its possible external power:

For the development of transport infrastructure, which is very important for sustainable transport, it is very important that the SDDC is united. Because, if the municipalities and the region agree when we insist on which roads and railways we want to expand, then there is a much greater likelihood that the national government will release the money needed. If we are not able to reach an agreement between the municipalities and the region we will not get a dime. So this is why the SDDC actually has a more important role than you might think. (I9)

The national transport infrastructure plan describes how the national transport budget should be distributed to infrastructure projects of national interest. The RVG, the subregions, and the municipalities are involved in this process by way of suggesting what infrastructure projects within Västra Götaland need national funding and what priorities they see as important (STA 2015). Experiences of prior negotiations with the national government show that if the RVG and the 49 municipalities can show a united front concerning the transport infrastructure development in Västra Götaland, they have good prerequisites for influencing the government's decisions (I3; I9; STA 2010). This means that the institutional context of the national transport infrastructure planning rewards a united region.

As shown in the quotation, the organizational prerequisite for a united region is the SDDC and its ability to reach consensus among its members. A unified SDDC is thus a major external resource for the region in negotiations with the national government. National infrastructure planning creates a situation where the subregions and the RVG are able to construct common counterparts: the national government and the other regions in Sweden (I7). If they act as united partners towards the national government, they are able to benefit in the competition with other regions for national funding (I1-I16). 
There are, however, situations where the SDDC has not managed to reach consensus, even though the ability to gain national influence has been possible (I3; I6). The possible internal and external power positions for the SDDC are thus not the only variables that drive policymaking in the committee. In the following analysis the identities of the members' original organizations show the complexity of performing integrated policymaking.

Municipal identity_-bringing relevance and legitimacy and preventing consensus

The municipalities have a very strong influence [on regional policymaking]. We have a tradition of being the region of municipalities. If I must be frank, at first, I thought it was a little odd that we were expected to channel local requests. For me, regional planning responsibility is to take holistic responsibility and think about what would benefit the region most. And then that might not be the same as what a municipal politician ran for office on 20 years ago. Now I'm bantering a little. But it gets really strange if that is supposed be the basis. So I think it's about trying to elevate the discussion in the SDDC about what it is we want and what kinds of opportunities are available. (I6)

I think the main problem is that the SDDC does not have a strong enough position. The problem is not that the Environment Committee or the Cultural Committee [...] have too little say in the matter, because if they had more say, the municipalities would absolutely not feel involved and then the region as a whole would not be able to become powerful. (I4)

The two quotations above illustrate the complex role of municipal identity in the SDDC. On the one hand, it works as a narrative providing the SDDC with relevance and legitimacy, which also makes regional policy relevant and legitimate. On the other hand, it is a strong original identity, which puts the municipalities in a resourceful position with respect to the RVG. This makes them able to go against the RVG and the formal structure of the SDDC, as well as being able to change it. Formally, the 16 subregional representatives in the SDDC represent their subregions, but they are originally political leaders in some of the municipalities. The municipal identity described here should be understood as a general identity all municipalities can agree on. This is based on the fact that all municipalities hold a land-use planning monopoly and that they are local governments that are held accountable by their citizens.

The current position of the SDDC as powerful in the regional transport policy process is said to be based on the municipalities' representation in the committee and their identity as municipalities. The SDDC thus gains legitimacy, relevance, and resources by having members with a municipal identity. Making the municipalities happy with their place in the regional decision-making structure is thus necessary for keeping the SDDC's position as influential. The municipalities must therefore feel they are involved in and can influence the regional decision-making (I1; I4; I5). One example of how this is done is the formal structure of the SDDC, where the subregional representatives are in majority (I1; I6; I4). Even if this has no practical consequences, since all committee decisions are taken in consensus (I6; I7), it has that appearance to give the feeling that the municipal representatives have a major position in the committee. The municipal identity holds the formal majority in the committee to provide the SDDC with legitimacy and relevance in the regional policy process.

As expressed in the second quotation above, there is an apprehension that the formal majority position of the subregional representatives is not enough to make the municipalities content with their participation in the SDDC structure. The municipalities must also be able to feel that they actually are influential and gain something from participating (I1; I6; I4; I5). One way suggested by the RVG representatives to assure that is to provide the SDDC with decision-making power over regional transport policy, thus transferring it from the RVG sectoral committees (I1; I4). The representation of a municipal identity in the SDDC is thus considered so important by the RVG that some of their leaders may consider giving SDDC a more formal decision-making role in the region, simply to keep the municipalities in the committee. However, despite the expressed importance of a representation of municipal identity in the SDDC, it is not considered desirable to let the municipal identity guide the representatives’ actions in the committee.

The municipal identity is considered problematic by both RVG and subregional representatives when it is expressed in the SDDC policymaking processes, problematic both for policy formation (I6) and for the SDDC's 
relevance and legitimacy (I3; I7; I8). The fear is that the SDDC's position in the regional policy process will be questioned if consensus cannot be reached. One example of when the municipal identity is regarded as problematic for policy formation can be seen in the first quotation in this part: an RVG representative described how traditional transport solutions are favored by municipalities outside the urban area of Gothenburg and how it affects the regional transport policy in the same direction. This happens because of the appearance of a strong municipal identity within the SDDC (I6). However, from the municipalities' perspective their influence in the SDDC may be their only chance to affect regional transport policy in line with their interests. The subregional representatives' prime identity, for themselves and for others, regardless of the formal SDDC rules, is still their municipal identity (I8). When the municipal identity diverges from the common idea and prevents consensusmaking, it is understood as a problem, which potentially interrupts and obstructs the power position of the SDDC in the region and in the external relations with the national government.

Subregional identities - the importance of geographical characteristics in policymaking

Since it is the Chair or the deputy Chair of a number of municipalities [who are subregional representatives in the $S D D C]$, you can never get away from the fact that their primary professional identity is as representatives of their municipality. For example, if I were to come home as the Chair of Gothenburg and say that I found investments in Skaraborg more important than those in the Gothenburg area, then I expect that people would say to me: "It's nice that you think so, but it is actually the last time you get to think something there, because now we will replace you." Now I exaggerate a little to make it clear, but the point is that the whole identity is geographic. (I8)

The quotation above puts focus on the essence of belonging to a certain place and the complex situation this creates for the subregional representatives in the SDDC. The quotation also points to the importance of geography in policymaking within the SDDC, the identification with certain physical characteristics and which place one belongs to have influence over the actions taken. In the SDDC this is visible alongside the division of the four subregions. These subregional identities give rise to the formation of alliances and majorities among the subregional representatives in the SDDC. This has implications for the transport policy formed by the SDDC and what the participants can agree on.

The subregional representatives in the SDDC represent a specific geographic area with certain characteristics. These characteristics and their relation to the issue at hand construct an organizational identity for each subregion. The subregions are different in many aspects; they have different geography and size of population, and their respective populations are dependent on different transport infrastructures and modes of transport. Therefore, they are affected differently by changes to the transport system. However, besides their differences there are also similarities in their characteristics and how they are affected by transport system change. The subregional identities may therefore both unite and divide the subregional representatives concerning issues of transport system development in general.

Transport infrastructure and commuting patterns in Västra Götaland cross municipal borders and the municipalities, and their subregions do not have enough resources or capability to develop transport solutions on their own. Transport infrastructure is therefore an issue of great importance, and the ability to influence its development is the major reason why the subregions choose to take part in the SDDC (I1; I3; I4; I5; I12). Their formation of a joint structure for the preparation of transport infrastructure decisions is one example showing how important the subregions deem transport infrastructure to be (I8; Västkom 2013). Where subregions are concerned, it is possible for them to gain more if they can agree on issues before negotiating with the RVG (I3; I8). In this way they can avoid conflicts between themselves and speak with a united voice against the RVG at the SDDC meetings.

The subregional representation in the SDDC does not correspond with the distribution of population within the region: Almost half of the total population in Västra Götaland lives in the Gothenburg subregion, and the other half of the population lives in the other three subregions (see Table 1) (Johansson and Niklasson 2013). This means that one-half of the population, who primarily live in urban areas, share four representatives in the SDDC, and the other half, who primarily live in smaller cities and in less densely populated areas, are 
represented by twelve members in the SDDC. The representatives who identify themselves with more "rural" characteristics are therefore in the majority among the subregional representatives. This is considered to have relevance for the SDDC's agenda. For example, in discussions of transport possibilities in the countryside the representatives of Fyrbodal, Sjuhärad, and Skaraborg subregions usually stick together, since they have similar problems and experiences (I12). The Gothenburg subregion has urban transport problems to deal with, which are not problematic for the others in the same way (I8). Consequently, a majority of the subregional representatives identify themselves with more "rural" characteristics, which enables them to put their transport problems high up on the SDDC agenda (I8). Development of existing and new transport infrastructure to attract more people and businesses is a matter of survival for rural areas and small towns (I3; I6; I12; I7). Concerning transport development decisions in the SDDC, this means that the major focus is on infrastructure development, foremost roads and private car solutions, rather than on railways and alternative, more environmentally sustainable solutions (I6; I12; I8).

Urban-oriented transport problems are to a large extent left out of the SDDC discussions (I6; I8; SDDC Notes, 2011-2013). This may be a consequence of the minority position of the Gothenburg subregional identity in the SDDC, but on the other hand, it is evident that Gothenburg is receiving much financial investment in its transport system (RVG 2015d). The position of Gothenburg as the economic motor of Västra Götaland provides the Gothenburg subregional identity with resources important for transport policy development for the entire region. In this role, the Gothenburg subregional identity is influential within the SDDC, since the other subregional representatives admit the importance of infrastructure investments in Gothenburg (I3; I12; I7). The minority position of Gothenburg in the SDDC should thus not affect its ability to place issues on the agenda. However, several of the urban transport solutions are connected to public transport, the only transport issue that is not supposed to be managed by the SDDC. Public transport in Västra Götaland is managed almost entirely by the RVG, as the owner of the public transport company (I15). The lack of urban transport considerations in the SDDC is thus probably not due to Gothenburg's minority position, but rather to the institutional context of the RVG.

Sectoral identities — one dominant identity in policymaking

The SDDC should own the issue and prepare for the RVG Executive Committee, and then the Executive Committee makes a decision. If the Regional Development Committee settles the issue too much, which would be likely because many involved officials are employed at its administration, then the risk is obvious that the focus is changed. But that was not the intention! The intention was to have collaboration with the municipalities in the SDDC and that the SDDC makes the decisions, not an individual RVG sectoral committee. (I1)

The reason why the Environment Committee [has less influence on transport planning] versus the Regional Development Committee, is that it is the Regional Development Committee which is responsible for developing the transport infrastructure plan. They are the ones who take the decisions. They are the ones who run these issues in the SDDC and they have a complete administration for that. (I11)

The two quotations above describe a conflict between the apprehensions of SDDC as an arena for integration, on the one hand, and on the other, the structure of where the formal responsibility and resources are placed. Even if the formal rules and the concern for municipal engagement prescribe that the sectors are not supposed to represent their own interests in the SDDC, the quotations above show that in transport policy formation sectoral identities are considered influential, primarily due to the distribution of resources.

Due to the theoretical framework, each sector is here considered to have its own identity (Gioia et al. 2013; Hendriks 1999). Politicians in sectoral committees are put in a position where they should concentrate on a specific sector. Even though the politicians have no specific profession, the officials at the administration, who inform and help them in decision-making, often have specific professions that are connected to the sector in question. This creates sectoral organizational identities, which are different for each sector. In the SDDC three sectoral committees are represented: the Culture Committee, the Environment Committee, and the Regional 
Development Committee. Concerning transport policy, the culture identity is not present in the material; therefore, the following text considers only regional development identity and environment identity.

The Regional Development Committee is responsible for regional transport infrastructure planning, education, and business development at the RVG (I13; RVG 2015e). This combination of transport infrastructure and business development concerns constructs a meaning of transport policy as managing the construction and reconstruction of transport infrastructure to achieve successful regional economic development (I13; I11). The representatives of the Regional Development Committee thus base their sectoral identity on the traditional idea that increasing transport availability is contributing to regional economic development (Andersson et al. 2008; Banister 2005).

The Environment Committee is responsible for monitoring all aspects of interference in the environment at the RVG. Concerning transport policy, it is primarily energy efficiency and decrease of the use of fossil fuels that are in focus (Hjalmarsson 2013; I11; RVG 2015f). The representatives of the Environment Committee thus base their sectoral identity on a general apprehension of environmental protection. In the case of transport infrastructure development this means that the most energy-efficient solutions and alternative fuels and vehicles are prioritized.

The result of the intention of more integration between sectors through the SDDC is that the transport infrastructure planning almost only concerns traditional transport solutions such as development and maintenance of roads and railways, with the major focus on roads (I6; SDDC Notes). In addition, in the priorities between different projects, considerations regarding transport demand and regional economic development are made, but other cross-sectoral considerations, such as environmental impact, are not discussed to any extent (I11; SDDC Notes 15/02/2011-03/12/2013). The Regional Development Committee holds formal responsibility for the development of the transport infrastructure plan and the distribution of financial resources. It is therefore supported by a department of officials with expert knowledge within the transport infrastructure field. The financial and expertise resources of the Regional Development Committee are argued to mean that it completely "owns the question" in the SDDC discussions of transport infrastructure planning (I4; I11; I13). In addition, the extended financial resources and status of transport infrastructure among politicians means the Regional Development Committee is made up of high-status politicians, which is obvious to the other members of the SDDC (I1; I11). Resources such as budget, expert knowledge, and status, due to the institutional context of the RVG, seem to influence the sectoral relationship in the SDDC.

From this it follows that there seems to be a hierarchy between the sectoral identities represented in the SDDC. The regional development identity is the dominant sectoral identity. It has major influence over agenda setting, discussions, and decisions through the position of the Regional Development Committee in the SDDC, both the positions of the politicians who are members and the role the department of officials play in transport development policymaking.

Concluding discussion: organizational identities and policy integration

This article's focus has been integrated policymaking to manage sustainable transport development. The case of the SDDC shows an organizational body with both local, regional, and sectoral representatives present, where policy integration may be performed. The analysis of organizational identities has shown that policy integration processes is depending on external position, differences in resources and relations to the issue of sustainable transport development.

The first conclusion to be drawn is that the policy integration process within the SDDC has been more focused along the vertical dimension than the horizontal, sectoral dimension. The main reason for this is the need of consensus in the SDDC, both for the committee and also for its members to gain an internally and externally resourceful position. Foremost, the external environment of the SDDC plays an important role, since national transport infrastructure planning forms an institutional context that rewards united regions. The surrounding organizations, such as the national government and other Swedish regions, become rivals (Kroezen and Heugens 2012) in this competition for resources. Committing to consensus in the SDDC thus becomes a survival strategy 
for the region and for the individual municipalities. Even though not every municipality will gain every time, the possibility of gaining promotes their will to contribute to consensus in the SDDC.

Furthermore the external consequences of consensus decisions may promote a homogenization of the decisionmakers involved, even though they owe their positions to their perceived differences. Striving for consensus and a resourceful position of the committee pushes the subregional representatives to, in most cases, give up their position related to their municipal and subregional identities in the policymaking. The ability to achieve consensus becomes more important than to uphold their original organizational identities. The emphasis on consensus making may therefore lead to a consensus overload (Koppenjan 2007). The fact that consensus is beneficial for the region speaks against encouraging conflict between the represented identities. Instead, homogenization is boosted to assure future consensus-making. A consensus overload is thus an obstacle to integration of policy. The representation and enforcement of different organizational identities clarify that there are differences to be managed in an integration process. The end result of that process may be a decision in consensus, but with the difference that the starting point is not that the original identities should be put aside but that they should be emphasized. Consensus, proven to be beneficial for the region, may thus not be beneficial for achieving integrated policymaking. In addition, as Koppenjan (2007) has argued, a consensus overload may also lead to problems with legitimacy and accountability.

Consensus-making is shown to be an obstacle for further sectoral integration of policy, since the issues on which it is possible reach consensus are all specific to a certain sector. The sectoral identity of the Regional Development Committee prescribes that transport infrastructure planning should contribute to regional economic development as its only goal, and this is also how transport issues are managed in the SDDC. As shown, the subregions with a population more dependent on the car for transportation are in the majority among the subregional representatives in the SDDC. The apprehension among both sectoral and subregional representatives is that these solutions will contribute to regional economic development. It is therefore possible to create consensus regarding transport infrastructure development for economic development. Other considerations of the transport system development, for example from an environmental point of view, are then out of scope. This is one reason why the responsibility of the SDDC; sustainable transport development, becomes limited to transport infrastructure in general and more specifically to roads and availability of cars.

The other reason for that limitation, as well as another obstacle for sectoral policy integration, is that there is one dominant sector identity. The Regional Development Committee holds both the financial and professional resources within the transport sector, within both the RVG and the SDDC. The Environmental Committee, on the other hand, does not even have as a task to ensure that environmental considerations of transport development are heard in the SDDC, since the RVG committees are not supposed to represent a specific sector. Making sectoral identities formally irrelevant and giving the impression that there is consensus on the nature of problem and solutions in turn gives an impression of integrated policymaking. However, the dominance of one sectoral identity over policymaking shows another picture: consensus-making risks sweeping different identities and their relations out of site and giving the most resource-rich identity the possibility to dominate decisionmaking.

To conclude, the case has shown that the organizational identities play different roles in relation to either vertical or sectoral policy integration. Vertical integration is enforced by the power resource possibilities available internally at the region and externally in the race for national funding. It is therefore also supported by the municipal and sub-regional identities. Sectoral integration is undermined by the resource inequalities between the involved sectors and also by the municipal and sub-regional identities' relations to the sustainable transport issue. Consequently, in the case of the SDDC vertical integration is not resulting in sectoral integration, rather it works prohibiting against sectoral integration.

\section{References}

Andersson, F., Ek, R., Molina, I. (2008). Regionalpolitikens geografi : regional tillväxt i teori och praktik. Lund: Studentlitteratur.

Banister, D. (2005). Unsustainable transport : city transport in the new century. London: Routledge. 
Banister, D. (2008). The sustainable mobility paradigm. Transport Policy, 15(2), 73-80.

DiMaggio P. J., Powell, W. W. (1983). The iron cage revisited: Institutional isomorphism and collective rationality in organizational fields. American Sociological Review, 48(2), 147-160.

Flyvbjerg, B. (2001). Making social science matter: Why social inquiry fails and how it can succeed again. Cambridge: Cambridge University Press.

Gioia, D. A., Patvardhan, S. D., Hamilton, A. L., Corley, K. G. (2013). Organizational identity formation and change. Academy of Management Annals, 7(1), 123-193

Glynn, M. A. (2008). Beyond constraint: How institutions enable identities. In R. Greenwood, C. Oliver, K. Sahlin, R. Suddaby (Eds.), The Sage handbook of organizational institutionalism (pp. 413-430). London: Sage.

Hendriks, F. (1999). Public policy and political institutions: The role of culture in traffic policy. Cheltenham: Elgar.

Hjalmarsson, L. (2015). Biogas as a boundary object for policy integration-The case of Stockholm. Journal of Cleaner Production, 98(0), 185-193.

Hjalmarsson, L. (2013). Regional transport policy: Progress towards environmental adaption? The $13^{\text {th }}$ World Conference on Transport Research, WCTR 2013, Rio de Janeiro, Brazil, July 15-18, 2013.

Hull, A. (2008). Policy integration: What will it take to achieve more sustainable transport solutions in cities? Transport Policy, 15(2), 94-103.

Hull, A. (2011). Transport matters: Integrated approaches to planning city-regions. London: Routledge.

Humphreys, M., Brown, A. D. (2002). Narratives of organizational identity and identification: A case study of hegemony and resistance. Organization Studies, 23(3), 421-447.

IEA (International Energy Agency) (2014a). Key World Energy Statistics. Paris.

IEA. (2014b). World Energy Outlook 2013. Paris.

Johansson, J., Niklasson, L. (2013). Kommunernas region - kommunernas inflytande i regionen. Stockholm: Sveriges kommuner och landsting.

Koppenjan, J. (2007). Consensus and conflict in policy networks: Too much or too little. In E. Sørensen, J. Torfing (Eds.), Theories of democratic network governance (pp. 133-152). Basingstoke: Palgrave Macmillan.

Kroezen, J. J., Heugens, P. (2012). Organizational identity formation: Processes of identity imprinting and enactment in the Dutch microbrewing landscape. In M. Schultz (Ed.), Constructing identity in and around organizations (pp. 89-127). Oxford: Oxford University Press.

Kvale, S., Brinkmann, S. (2009). InterViews: Learning the craft of qualitative research interviewing, 2nd ed. Los Angeles: Sage.

March, J. G., Olsen, J. P. (2008). The logic of appropriateness. In M. Moran, M. Rein, R. F. Goodin (Eds.), The Oxford handbook of public policy (pp. 689-708). Oxford: Oxford University Press.

Nyström, J. (2003). Planeringens grunder: en översikt. Lund: Studentlitteratur.

Olsson, L., Hjalmarsson, L., Wikström, M., Larsson, M. (2015). Bridging the implementation gap: Combining backcasting and policy analysis to study renewable energy in urban road transport. Transport Policy, 37(0), 7282.

Rose, L. E., Ståhlberg, K. (2005). The Nordic countries: Still the promised land. In B. Denters, L. E. Rose (Eds.), Comparing local governance: Trends and developments (pp. 83-99). New York Palgrave Macmillan.

Scott, W. R. (2014). Institutions and organizations: Ideas, interests and identities. Thousand Oaks, CA: Sage.

Selznick, P. (1984). Leadership in administration: A sociological interpretation. Berkeley: University of California Press. 
Selznick, P. (1992). The moral commonwealth: Social theory and the promise of community. Berkeley: University of California Press.

Selznick, P. (1996). Institutionalism “old” and “new.” Administrative Science Quarterly, 41(2), 270-277.

SEA (Swedish Energy Agency). (2015) Transportsektorns energianvändning 2014 (Energy use in the transport system). ER 2015:01. Eskilstuna

Stead, D., Geerlings, H., Meijers, E. (2004). Policy integration in practice: The integration of land use planning, transport and environmental policy-making in Denmark, England and Germany. Delft: DUP Science.

Stead, D. (2008). Institutional aspects of integrating transport, environment and health policies. Transport Policy 15(3), 139-148.

Stead, D., Meijers E. (2009). Spatial planning and policy integration: Concepts, facilitators and inhibitors. Planning Theory and Practice, 10(3), 317-332.

Sørensen, E., Torfing, J. (2007). Theories of democratic network governance. Basingstoke: Palgrave Macmillan. Tesch, R. (1990). Qualitative research: Analysis types and software tools. London: Palmer.

Ugland, T., Veggeland, F. (2006). Experiments in food safety policy integration in the European Union. Journal of Common Market Studies, 44(3), 607-624.

Underdal, A. (1980). Integrated marine policy. What? Why? How? Marine Policy 4(3): 159-169.

WCED (World Commission on Environment and Development). (1987). Our common future. United Nations World Commission on Environment and Development. Oxford: Oxford University Press. 
Appendix 1. Empirical sources

SDDC documents

SDDC Instructions (2010) 10/19/2010

SDDC Notes (2011) 15/02/2011

SDDC Notes (2011) 01/04/2011

SDDC Notes (2011) 23/06/2011

SDDC Notes (2011) 30/08/2011

SDDC Notes (2011) 04/10/2011

SDDC Notes (2011) 22/11/2011

SDDC Notes (2012) 31/01/2012

SDDC Notes (2012) 30/03/2012

SDDC Notes (2012) 31/05/2012

SDDC Notes (2012) 11/09/2012

SDDC Notes (2012) 16/10/ 2012

SDDC Notes (2012) 04/12/2012

SDDC Notes (2013) 29/01/2013

SDDC Notes (2013) 05/03/2013

SDDC Notes (2013) 23/05/2013

SDDC Notes (2013) 25/06/2013

SDDC Notes (2013) 03/09/2013

SDDC Notes (2013) 15/10/2013

SDDC Notes (2013) 03/12/2013

Other documents

RVG. (2015a). Västra Götaland - vårt område, available at: http://www.vgregion.se/sv/Vastra-

Gotalandsregionen/startsida/Om-Vastra-Gotalandsregionen/-Vastra-Gotaland/, accessed 9 June 2015.

RVG. (2015b). Vägen till Västra Götalandsregionen, available at: http://www.vgregion.se/sv/Vastra-

Gotalandsregionen/startsida/Om-Vastra-Gotalandsregionen/Vagen-till-Vastra-Gotalandsregionen/, accessed 9 June 2015.

RVG. (2015c). About Region Västra Götaland, available at: http://www.vgregion.se/en/VastraGotalandsregionen/Home/About-us/, accessed 9 June 2015.

RVG. (2015d). Västsvenska paketet, available at: http://www.vgregion.se/sv/Vastra-

Gotalandsregionen/startsida/Regionutveckling/Infrastruktur/Det-vastsvenska-infrastrukturpaketet/Fragor-ochsvar/, accessed 10 June 2015. 
RVG. (2015e). Development in Västra Götaland, available at: http://www.vgregion.se/en/VastraGotalandsregionen/Home/Regional-development/, accessed 12 June 2015.

RVG. (2015f). Networking for the environment in Västra Götaland, available at: http://www.vgregion.se/en/Vastra-Gotalandsregionen/Home/Environment/, accessed 12 June 2015.

RVG. (2011). Lokal förankring av utvecklingsfrågorna - bilaga 1 i: Morgondagens innovativa Västra Götaland - hur då?, available at: http://www.vgregion.se/sv/VastraGotalandsregionen/startsida/Regionutveckling/Naringsliv/Program/Tillvaxtarbete/Nyheter/Vastra-Gotalandsprioriteringar-i-det-framtida-tillvaxtarbetet/

RVG. (2008). A Good Life-A Presentation of Region Västra Götaland, available at: http://www.vgregion.se/upload/English_common/Good_life_Vastra_Gotaland.pdf

STA (Swedish Transport Administration). (2015). Planer och beslutsunderlag, available at: http://www.trafikverket.se/Foretag/Planera-och-utreda/Planer-och-beslutsunderlag/, accessed 10 June 2015.

STA (Swedish Transport Administration). (2010). Avtal om medfinansiering av transportslagsövergripande infrastrukturåtgärder i Västsverige, TRV 2010/35899.

Västkom (2013). Verksamhetsplan 2014 för Västkom.

Interviews

I1, RVG Culture Committee representative in the SDDC, 4 December 2012.

I2, RVG Regional Development Committee representative in the SDDC, 19 November 2012.

I3, Skaraborg subregion representative in the SDDC, 19 February 2013.

I4, RVG Regional Development Committee representative in the SDDC, 14 January 2013.

I5, RVG Environment Committee representative in the SDDC, 5 December 2012.

I6, RVG Regional Development Committee representative in the SDDC, 14 January 2013.

I7, Sjuhärad subregion representative in the SDDC, 18 December 2012.

I8, Gothenburg subregion representative in the SDDC, 21 January 2013.

I9, RVG Environment Committee representative in the SDDC, 4 December 2012.

I10, RVG official at the Regional Development administration, 27 November 2012.

I11, RVG official at the Environment administration, 28 November 2012.

I12, Official at the Fyrbodal subregion, 18 February 2013.

I13, RVG official at the Regional Development administration, 5 December 2012.

I14, RVG Public Transport Committee, no representation in the SDDC, 3 December 2012.

I15, RVG official at the Public Transport administration, 27 November 2012.

I16, RVG Public Transport Committee, no representation in the SDDC, 20 November 2012. 